\title{
FAKTOR PREDISPOSISI SEBAGAI PENENTU PEMANFAATAN POS PEMBINAAN TERPADU PENYAKIT TIDAK MENULAR
}

\author{
Sri Sugiarsi ${ }^{1}$, Ana Wigunantiningsih ${ }^{2}$, Erna Adita Kusumawati ${ }^{3}$ \\ sri.sugiarsi14@gmail.com \\ ${ }_{1,2,3)}$ STIKes Mitra Husada Karanganyar \\ Jalan A Yani No 168 Papahan, Tasikmadu, Karanganyar, Jawa Tengah, Indonesia
}

\begin{abstract}
Non-infectious disease is one of the major causes of death in the world. Non-infectious disease prevention efforts in Indonesia are carried out through Integrated Service Post. The implementation of integrated service post of non-infectious disease in Mojolaban still encounters various problems. One of them is low utilization of integrated service post of non-infectious disease. This research was aimed at analyzing predisposition factors as determinant of integrated service post utilization of non-infectious disease. This research was conducted in a village in which the integrated service post was under the working area of PuskesmasMojolaban in 2018. The research design was analytical observational. The sample was all people living in the village with integrated service post utilization of non-infectious disease which was 152 people. The sampling used was multi stage random sampling. The data were analyzed through binary logistic regression. The research result showed that knowledge, attitude, and culture influenced the utilization of integrated service post utilization of non-infectious disease as well as age, gender, education. Meanwhile, occupation did not influence the integrated service post utilization of noninfectious disease.
\end{abstract}

Keywords: predisposition, integrated service post, non-infectious disease

\begin{abstract}
Abstrak
Penyakit Tidak Menular (PTM) sebagai salah satu penyebab utama kematian di dunia. Upaya Penanggulangan PTM di Indonesia dilakukan melalui posbindu (Pos Pelayanan Terpadu) PTM. Pelaksanaan Posbindu PTM di Mojolaban masih menghadapi berbagai masalah, salah satu diantaranya adalah rendahnya pemanfaatan posbindu PTM. Penelitian ini bertujuan untuk menganalisis faktor predisposisi sebagai penentu pemanfaatan posbindu PTM. Penelitian ini dilakukan di desa dengan posbindu yang berada di wilayah kerja Puskesmas Mojolaban tahun 2018. Rancangan penelitian ini adalah observasional analitik. Sampel adalah seluruh masyarakat yang bertempat tinggal di desa dengan posbindu PTM sebesar 152 orang. Teknik pengambilan sampel yaitu multi stage random sampling. Analisis data dengan menggunakan regresi logistik biner. Hasil penelitian menunjukkan pengetahuan, sikap, budaya mempengaruhi pemanfaatan posbindu PTM, serta umur, jenis kelamin, pendidikan, pekerjaan tidak mempengaruhi pemanfaatan posbindu PTM.
\end{abstract}

Kata kunci: predisposisi, posbindu, penyakit tidak menular

\section{Pendahuluan}

Proporsi kematian akibat penyakit tidak menular (PTM) di Indonesia mengalami peningkatan. Berdasarkan hasil Survei Kesehatan Rumah Tangga (SKRT) tahun 1995, tahun 2001, dan Riskesdas tahun 2007 selalu terjadi peningkatan yakni dari 41,7\% (tahun 1995), 49,9\% (tahun 2001) menjadi 59,5\% (tahun 2007). Terjadi peningkatan prevalensi PTM, hipertensi dari $7,6 \%$ pada tahun
2007 menjadi 9,5\% pada tahun 2013. Hal yang sama untuk stroke meningkat dari 8,5 (2007) menjadi 12.1, diabetes melitus dari $1,1 \%$ (2007) menjadi $2,1 \%$ (2013). ${ }^{[1,2]}$

Peningkatan PTM juga terjadi di Kabuapten Sukoharjo dimana tahun 2015 (2.750 kasus), tahun 2016 (3.150 kasus), dan tahun 2017 (3.805 kasus). ${ }^{\text {[3] }}$ Peningkatan prevalensi PTM dapat berdampak terhadap peningkatan beban 
pembiayaan kesehatan yang harus ditanggung negara dan masyarakat. Penyandang PTM memerlukan biaya yang relatif lebih mahal, terlebih bila kondisinya berkembang menjadi kronik dan terjadi komplikasi. PTM menghabiskan biaya yang cukup besarbila dibandingkan dengan biaya pengobatan tertinggi dari seluruh penyakit menular.Upaya Penanggulangan PTM di Indonesia dilakukan melalui posbindu PTM dan pandu PTM menjadi salah satu target dan indikator pengendalian PTM. Kegiatan posbindu PTM di masyarakat dan pandu PTM di puskesmas merupakan upaya promotif dan preventif melalui deteksi dini faktor resiko PTM. $^{[4]}$

Berdasarkan kajian literatur, pelaksanaan Posbindu pada hampir seluruh wilayah di Indonesia masih menghadapi berbagai masalah. Masalahmasalah tersebut, diantaranya yaitu: cakupan sasaran masih rendah $(<40 \%)$, kader kurang berperan, tidak adanya penyuluhan kesehatan, tidak alat kolesterol total dan Trigliserid, kurangnya koordinasi antara kader dengan petugas puskesmas, komitmen puskesmas selaku tim pembina kurang, kurangnya kerja sama lintas sektor program Posbindu, masyarakat tidak termotivasi untuk menjadi kader. ${ }^{[5,6]}$

Tidak terdapat hubungan antara pendidikan dengan keaktifan kunjungan posbindu ( $>0.05)$. Responden yang mempunyai pengetahuan rendah mempunyai peluang untuk 61,5 kali dalam hal tidak memanfaatkan posbindu dibanding responden yang mempunyai pengetahuan tinggi. Ada hubungan peran kader dengan pemanfaatn posbindi $(\mathrm{p}=0.001)$. Yuliah (2001) dalam hasil penelitiannya menunjukkan bahwa faktor pendidikan, persepsi sakit, sikap petugas, penyandang dana, jarak, biaya transportasi berhubungan dengan pemanfaatan puskesmas. Dari keenam faktor yang berhubungan dengan pemanfaatan puskesmas, ternyata persepsi sakit yang paling dominan berhubungan dengan pemanfaatan Puskemas. ${ }^{[7,8]}$

Model kepercayaan kesehatan dimana ketika setiap individu memanfaatkan pelayanan kesehatan tergantung tiga kategori utama diantaranya; faktor predisposisi, faktor pendukung dan faktor penguat. Faktor predisposisi meliputi;karakteristik demografi (umur, jenis kelamin), struktur sosial (pendidikan, pekerjaan, kesukuaan/ras), pengetahuan, nilai/budaya, sikap. ${ }^{[9]}$

Dua desa (Desa Triyagan dan Desa Laban) di kecamatan Mojolaban yang telah mempunysi posbindu PTM namun cakupan masyarakat yang memanfaatkan posbindu PTM masih rendah $(10,8 \%)$. Faktor predisposisi diduga sebagai faktor penyebabnya. Tujuan penelitian ini adalah untuk menganalisis faktor predisposisi sebagai penentu pemanfaatan posbindu PTM

\section{Metode Penelitian}

Rancangan penelitian ini adalah observasional analitik dengan pendekatan cross sectional yang digunakan untuk menganalisis variabel sebab dan akibat yang terjadi pada obyek penelitian diukur atau dikumpulkan secara simultan. Populasi adalah seluruh masyarakat bertempat tinggal di desa dengan posbindu PTM di wilayah kerja Puskesmas Mojolaban. Sampel adalah seluruh masyarakat yang bertempat tinggal di desa dengan posbindu PTM sebesar 152 orang. Teknik pengambilan sampel yaitu multi stage random sampling. Variabel bebas yaitu faktor predisposisi meliputi; umur, jenis kelamin, pendidikan, pekerjaan, pengetahuan, sikap, budaya/kebiasaan. Dan sebagai variabel terikat yaitu pemanfaatan posbindu PTM. Penelitian ini menggunakan data primer yang dikumpulkan dengan wawancara menggunakan kuesioner terstruktur. Analisis data dalam penelitian menggunakan analisis regresi logistik biner.

\section{Hasil dan Pembahasan}

Karakteristik Predisposisi 
Penelitian dilakukan terhadap 152 orang responen. Sebanyak 80 responden $(52,6 \%)$ memanfaatkan posbindu PTM dan 72 responden $(47,4 \%)$ tidak memanfaatkannya. Selisih antara yang memanfaatan dengan yang tidak memanfaatkan hanya sedikit yaitu $5,2 \%$; Sebanyak 91 orang $(59,9 \%)$ berjenis kelamin perempuan, berpendidikan tinggi; 78 0rang (51,3\%). Responden yang bekerja; 84 orang $(55,3 \%)$, berpengetahuan tinggi; 88 orang $(57,9 \%)$ dan berpengetahuan rendah; 64 orang $(42,1 \%)$; bersikap positif; 98 orang $(64,5 \%)$, sedangkan bersikap negatif; 54 orang $(35,5 \%)$. Responden mempunyai budaya atau kebiasaan mencari pengobatan ke tenaga kesehatan(nakes); 83 orang $(54,6 \%)$ lebih banyak dibanding dengan yang mempunyai kebiasaan ke non nakes; $69(45,4 \%)$.

Tabel 1 Karakteristik Predisposisi

\begin{tabular}{|c|c|c|}
\hline $\begin{array}{l}\text { Karakteristik } \\
\text { Predisposisi }\end{array}$ & jumlah & $\%$ \\
\hline \multicolumn{3}{|l|}{ Umur } \\
\hline $\begin{array}{l}15 \text { s.d } 45 \text { tahun } \\
\text { (muda) }\end{array}$ & 63 & 41,4 \\
\hline$>45$ tahun(tua) & 89 & 58,6 \\
\hline \multicolumn{3}{|l|}{ Jenis Kelamin } \\
\hline Laki - laki & 61 & 40,1 \\
\hline Perempuan & 91 & 59,9 \\
\hline \multicolumn{3}{|l|}{ Pendidikan } \\
\hline rendah & 74 & 48,7 \\
\hline Tinggi & 78 & 51,3 \\
\hline \multicolumn{3}{|l|}{ Pekerjaan } \\
\hline Tidak Bekerja & 68 & 44,7 \\
\hline bekerja & 84 & 55,3 \\
\hline \multicolumn{3}{|l|}{ Pengetahuan } \\
\hline Rendah & 64 & 42,1 \\
\hline Tinggi & 88 & 57,9 \\
\hline \multicolumn{3}{|l|}{ Sikap } \\
\hline Negatif & 54 & 35,5 \\
\hline Positif & 98 & 64,5 \\
\hline \multicolumn{3}{|l|}{ Budaya-kebiasaan } \\
\hline Non Nakes & 69 & 45,4 \\
\hline Nakes & 83 & 54,6 \\
\hline \multicolumn{3}{|l|}{ Pemanfaatan } \\
\hline Memanfaatkan & 80 & 52,6 \\
\hline $\begin{array}{l}\text { Tidak } \\
\text { Memanfaatkan }\end{array}$ & 72 & 47,4 \\
\hline
\end{tabular}

Berdasarkan Tabel 1 dapat diartikan bahwa cakupan sasaran pemanfaatan posbindu PTM belum mencapai $60 \%$. Data karakteristik predisposisi tingkat pengetahuan tinggi terhadap posbindu PTM dan sikap positif masyarakat terhadap posbindu PTM; capainnya juga masih kurang dari 60\%. Karakteristik predisposisi akan mempengaruhi seseorang untuk menggunakan pelayanan kesehatan. Karateristik ini digunakan untuk menggambarkan fakta bahwa tiap individu mempunyai kecenderungan yang berbeda - beda untuk menggunakan pelayanan kesehatan Setiap individu mempunyai karakteristik yang berbeda, dan punya tipe, frekuensi penyakit, serta pola pemanfaatn fasilitas pelayanan yang berbeda - beda. ${ }^{[10]}$

Analisi Regresi Logistik Biner

Tabel 2 Hasil Analisis Regresi Logistik

\begin{tabular}{llllll}
\multicolumn{7}{c}{ Biner } \\
\hline Variabel & B & Wald & p-value & $\operatorname{Exp(B)}$ & $\mathbf{9 5 \% C I}$ \\
\hline umur & 0,074 & 0.009 & 0,923 & 1,077 & $0,241-4,811$ \\
Jenis kelamin & 1,621 & 3,376 & 0,044 & 3,657 & $1,152-12,846$ \\
Pendidikan & $-0,190$ & 0,043 & 0,867 & 0,836 & $0,137-4,990$ \\
Pekerjaan & 0,473 & 0,445 & 0,505 & 1,605 & $0,400-6,444$ \\
Pengetahuan & 1,566 & 4,374 & 0,036 & 4,789 & $1,104-20,786$ \\
Sikap & 1,489 & 4,219 & 0,040 & 4,434 & $1,071-18,363$ \\
Budaya & 3,350 & 10,084 & 0,001 & 28,499 & $3,605-225,292$ \\
\hline
\end{tabular}

Umur

Hasil analisis regresi logistik bahwa Umur tidak mempengaruhi pemanfaatan posbindu PTM pada $\mathrm{p}$ value $=0,923$. Umur $>45$ tahun (tua) lebih banyak yang memanfaatkan dibanding dengan yang berumur(15-45tahun). Hasil ini sesuai dengan Rusdiyanti (2017) dan Lestari(2011) bahwa tidak ada perbedaan pemanfaatan pelayanan kesehatan antara responden yang berumur tua dengan yang muda. [7,8] Faktor Umur berperan dalam kesinambungan pelayanan kesehatan di fasilitas kesehatan. Semakin bertambah umur maka akan semakin bertambah masalah keseghatan dan akan berakibat pada semakin bertmabahnya pemanfaatn pelayanan kesehatan. Oleh karena itu pemanfaatan posbindu PTM secara rutin akan mengurangi bertambahnya masalah kesehatan di usia tua. 
Jenis Kelamin

Jenis kelamin mempengaruhi pemanfatan posbindu PTM (p value $=0,044)$. Responden perempuan berpeluang 3,66 kalinya untuk memanfaatkan posbindu PTM jika dibandingkan dengan laki - laki. Perempuan mempunyai alat reproduksi yang lebih komplek dibanding laki laki, hal ini juga akan berpengaruh dalam mengakses atau memanfaatkan pelayanan kesehatan. Hasil penelitian ini tidak sejalan dengan Rusdiyanti (2017), Rahmayanti (2017), Lestari (2011) ${ }^{[7,8,9]}$ yang menyatakan bahwa ada hubungan antara umur dengan pemanfaatn posbindu. Secara teoritis, bahwa jenis kelamin merupakan faktor demografi yang berpengaruh terhadap pemanfaatan pelayanan kesehatan. ${ }^{[9]}$

\section{Pendidikan}

Pendidikan tidak mempengaruhi pemanfaatan posbindu PTM (p value $=0,867)$. Secara teori pendidikan formal akan mempengaruhi pengetahuan seseorang sehingga apabila pendidikan formal tinggi maka tingkat pengetahuannya akan lebih tinggi dibanding yang berpendidikan formal rendah. Namun dalam penelitian ini ditemukan tidak semua responde yang berpendidikan tinggi mempunyai pengetahuan yang baik tentang posbindu PTM. Hasil penelitian ini tidak sejalan dengan Dewi (2012) dan Rusdiyanti(2017) bahwa ada hubungan antara pendidikan dengan pemanfaatn posbindu lansia. ${ }^{[7,8]}$ Pendidikan yang tinggi diharapkan lebih mudah menerima pesan - pesan kesehatan.

\section{Pekerjaan}

Hasil analisis regresi logistik menunjukkan bahwa pekerjaan tidak mempengaruhi pemanfaatan posbindu PTM $(p=0,505)$. Dalam penelitian ini responden yang tidak bekerja cenderung lebih banyak memanfaatkan posbindu PTM. Mereka lebih banyak mempunyai waktu luang dan kesempatan untuk berkunjung ke posbindu PTM secara teratur sesuai jadwal. Dan mereka yang tidak memanfaatkan posbindu beralasan bahwa mereka mempunyai KIS/BPJS yang bisa dimanfaatkan untuk kontrol kesehatan di puskesmas. Hasil penelitian ini berbeda dengan Rahmayanti(2017) bahwa ada hubungan status pekerjaan dengan pemnafaatan pelayanan kesehatan.

Pengetahuan

Hasil analisis regresi logistik biner bahwa pengetahuan mempengaruhi pemanfaatan posbindu PTM(p value $=0,036)$. Nilai $\operatorname{Exp}(B)$ atau $\mathrm{OR}=4,789$. Hal ini berarti kecenderungan seseorang yang mempunyai tingkat pengetahuan tinggi untuk berkunjung ke posbindu PTM 5 kalinya dibandingkan dengan yang berpengetahuan rendah. Hasil penelitian ini sejalan dengan Dewi (2012), Rohmayanti (2017), Lestari (2013) yang menyampaikan bahwa ada hubungan pengetahuan dengan pemanfaatn posbindu. ${ }^{[7,8,9]}$ Pengetahuan merupakan faktor yang sangat penting dalam menentukan tindakan seseorang. [10]. Dalam penelitian ini responden yang memanfaatkan adalah mereka mengetahui kegiatan apa saja yang dilakukan dan jadwal kegiatan di posbindu PTM. Pengetahuan yang baik tidak menjamin seseorang akan berperilaku baik. Responden yang berpengatuan baik namun tidak memanfaatkan posbindu PTM; mereka beralasan malu untuk berkunjung ke posbindu PTM. Pemberian informasi dan sosialisasi PTM, upaya pengendalian, serta manfaatnya, kepada masyarakat secara terus menerus akan meningkatkan pengetahuan, kesadaran masyarakat serta minat untuk berkunjung ke posbindu PTM.

Sikap

$\mathrm{P}$ value $==0,032, \mathrm{H} 0$ ditolak; variabel sikap mempengaruhi kunjungan posbindu PTM. Nilai $\operatorname{Exp}(\mathrm{B})=5,542$. Hal ini berarti kecenderungan seseorang yang mempunyai sikap positif lebih tinggi untuk berkunjung ke posbindu PTM 5 kalinya dibandingkan dengan 
yang bersikap negatif. Hasil penelitian ini sesuai dengan Green yang menyampaikan bahwa sikap merupakan faktor yang berperan dalam perilaku kesehatan. Namun dalam penelitian ini masih ditemukan responden yang tidak memanfaatkan posbindu PTM meskipun mereka bersikap positif. Hal ini dapat disimpulkan bahwa sikap positif tidak otomatis dapat berperilaku positif. Untuk merubah sikap tersebut diperlukan tindakan nyata dan faktor pendukung lain dalam mengkondisikan sikap tersebut. ${ }^{[10]}$ Hasil penelitian ini sejalan dengan Rusdiyanti(2017), Rahmayanti(2017), Lestari(2011) yang menyatakan bahwa ada hubungan sikap dengan pemnafaatan posbindu. ${ }^{[7,8,9]}$

Budaya

Budaya dalam penelitian ini adalah kebiasaan masyarakat dalam upaya untuk mencari pengobatan (tenaga kesehatan atau non tenaga kesehatan). Hasil analisis regresi logistik biner bahwa budaya kebiasaan dalam upaya pencarian pengobatan mempengaruhi pemanfaatan/kunjungan posbindu PTM ( $\mathrm{P}$ value $=0,001)$. Nilai $\operatorname{Exp}(\mathrm{B})=4,115$. $\mathrm{Hal}$ ini berarti kecenderungan seseorang yang mempunyai budaya berobat ke tenaga kesehatan lebih tinggi untuk berkunjung ke posbindu PTM 4 kalinya dibandingkan dengan yang berobat ke non nakes. Hasil penelitian ini sejalan dengan Rusdiyanti(2017), Lestari(2011) bahwa ada hubungan budaya dengan pemanfaatan posbindu lansia. ${ }^{[7,8]}$ Setiap individu mempunyai kepercayaan yang berbeda - beda terhadap manfaat kunjungan posbindu PTM. Dalam penelitian ini masih ditemukan 45,4\% masyarakat mempunyai budaya pencarian pengobatan ke non tenaga kesehatan. Artinya masyarakat belum sepenuhnya percaya terhadap upayaupaya pemerintah dalam meningkatkan derajat kesehatan masyarakat melalui posbindu PTM. Oleh karena itu diperlukan upaya pendekatan kesehatan yang lebih komprehensif.

\section{Kesimpulan}

Faktor predisposisi sebagai penentu dalam pemanfaatan posbindu PTM adalah jenis kelamin, pengetahuan dan sikap serta budaya pencarian pengobatan. Disarankan bagi kader posbindu dan petugas kesehatan untuk melakukan penyuluhan terkait posbindu PTM secara periodik sehingga masyarakat mampu merubah sikap dan budaya yang tidak baik.

\section{Daftar Pustaka}

[1] World Health Organization. Global Status Report On

Noncommunicable Desases. Genewa: World Health Organization. 2011

[2] Kemenkes RI. Laporan hasil Riset Kesehatan Dasar(Riskesdas) Tahun 2013. Jakarta: Badan Penelitian dan Pengembangan Kesehatan Kemenkes RI. 2013

[3] Dinas Kesehatan Provinsi Jawa Tengah. Profil Kesehatan Provinsi. Semarang: Dinas Kesehatan Provinsi Jawa Tengah ; 2015. $71 \mathrm{p}$. 2015

[4] Kementerian Kesehatan RI. Petunjuk Teknis: Penyelenggaraan Pos Pembinaan Terpadu Penyakit Tidak Menular (PosbinduPTM). Jakarta: Direktorat Jendral Pengendalian Penyakit dan Penyehatan Lingkungan dan Direktorat Pengendalian Penyakit Tidak Menular Kemenkes RI. 2014

[5] Kementerian Kesehatan RI. Peraturan Menteri Kesehatan Republik Indonesia nomor 5 tahun 2017 tentang Rencana Aksi Nasional Penanggulangan Penyakit Tidak Menular. Jakarta: Kementrian Kesehatan RI. 2017

[6] Sari D, Savitri M. Faktor - Faktor Yang Berhubungan Dengan Pemanfaatan Ponsbidu Penyakit Tidak Menular d Wilayah Kerja Puskesmas Setiabudi Kota Jakarta. Jurnal Kebijakan Kesehatan Indonesia. 2018. 7:2: 49 - 56. 
[7] Rusdiyanti I. Faktor Yang Mempengaruhi Keaktifan Kunjungan Pos Pembinaan Terpadu Penyakit Tidak Menular Di Desa. Jurnal Kemas. 2017. 10:1:37 -45.

[8] Lestari, P., Soeharyo H., \& Kris P,. Beberapa Faktor yang Berperan terhadap Keaktifan Kunjungan Lansia ke Posyandu. Jurnal Media Medika Indonesiana. 2011. 45:2: $65-74$.

[9] Dewi H, Eka W. Pengetahuan dan Sikap Terhadap Keaktifan Penduduk Ke Posbindu Penyakit Tidak Menular. Jurnal Kemas. 2015. 11:1:8 - 14.

[10] Notoatmodjo. Promosi Kesehatan Teori dan Aplikasi. Rineka Cipta: Jakarta. 2010. 